\title{
Population analysis of pharmacogenetic polymorphisms related to acute lymphoblastic leukemia drug treatment
}

\author{
Marcela A. Chiabai ${ }^{\mathrm{a}}$, Tulio C.L. Lins ${ }^{\mathrm{b}}$, Robert Pogue ${ }^{\mathrm{a}}$ and Rinaldo W. Pereira ${ }^{\mathrm{a}, \mathrm{b}, *}$ \\ ${ }^{a}$ Programa de Pós-Graduação em Ciências Genômicas e Biotecnologia, Universidade Católica de Brasília, \\ Brasilia, DF, Brazil

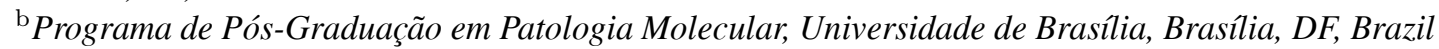

\begin{abstract}
This study aimed to evaluate in the Brazilian population, the genotypes and population frequencies of pharmacogenetic polymorphisms involved in the response to drugs used in treatment of acute lymphoblastic leukemia (ALL), and to compare the data with data from the HapMap populations. There was significant differentiation between most population pairs, but few associations between genetic ancestry and SNPs in the Brazilian population were observed. AMOVA analysis comparing the Brazilian population to all other populations retrieved from HapMap pointed to a genetic proximity with the European population. These associations point to preclusion of the use of genetic ancestry as a proxy for predicting drug response. In this way, any study aiming to correlate genotype with drug response in the Brazilian population should be based on pharmacogenetic SNP genotypes.
\end{abstract}

Keywords: SNPs, Brazilian population, pharmacogenetic polymorphisms, HapMap

\section{Introduction}

Leukemia is a neoplastic disease derived from clonal expansion of blasts, which accumulate in the bone marrow preventing the formation of blood cells. Acute Lymphoblastic Leukemia (ALL) is the most common type of childhood cancer, corresponding to $25 \%$ of all cancers in children and $75 \%$ of leukemia cases $[9,19$, 22]. Progress in drug development and chemotherapy protocols has brought the cure rate for ALL to nearly $80 \%$ currently $[21,24]$. However, the response to treatment and the presence of side effects vary among patients due to factors such as age, sex and genetics [10].

For instance, the antifolate Methotrexate (MTX), an antineoplastic agent with immunosuppressive proper-

\footnotetext{
* Corresponding author: Programa de Pós-Graduação em Ciências Genômicas e Biotecnologia, Universidade Católica de Brasília, SGAN 916 Norte, Av. W5 - Módulo B, Bloco C, Sala 207, Brasília, DF, Brazil - CEP 70790-160. Tel.: +55 613448 7222; Fax: +55 61 3347 4797; E-mail: rinaldo.pereira@catolica.edu.br.
}

ties is used in the treatment of ALL and other diseases, such as rheumatoid arthritis [16,29]. MTX is transported to the inside of the cell by the reduced folate carrier (RFC), which is very important to MTX efficacy [12, 16]. The enzymes from folate pathways have single nucleotide polymorphisms (SNPs) that can influence the effects of MTX, and the study of these SNPs can help in the management of patient care [5,16,32], suggesting that population or inter-individual genetic differences may play an important role in pharmacogenetics responses [31]. The variability in the response to drugs occurs within and between populations and to individualize treatment it is necessary to characterize the genetic variations between individuals.

Admixed populations are prone to generating false negative/positive or spurious associations [28] due to the admixture stratification and different drug response phenotypes [26]. Thus, in such populations, studies may require the use of ancestry-informative markers (AIMs) to control for population stratification in or- 
Table 1

Pharmacogenetics polymorphisms and implicated drugs

\begin{tabular}{|c|c|c|c|c|}
\hline \multirow[b]{2}{*}{ Polymorphism } & \multirow[b]{2}{*}{ dbSNP ID } & \multirow{2}{*}{$\begin{array}{c}\text { Implicated drugs } \\
\text { (Known and Suspected) }\end{array}$} & \multicolumn{2}{|c|}{ Allele } \\
\hline & & & 1 & 2 \\
\hline MTHFR 677C>T & rs 1801133 & MTX & $\mathrm{C}$ & $\mathrm{T}$ \\
\hline$M T H F R$ 1298A $>\mathrm{C}$ & rs 1801131 & MTX & A & $\mathrm{C}$ \\
\hline$G S T P 1313 \mathrm{~A}>\mathrm{G}$ & rs1695 & GC, MTX & A & $\mathrm{G}$ \\
\hline$R F C 180 \mathrm{G}>\mathrm{A}$ & rs 1051266 & MTX & G & A \\
\hline GSTP1 A114V & rs1138272 & GC, MTX & $\mathrm{C}$ & $\mathrm{T}$ \\
\hline$G G H 452 \mathrm{C}>\mathrm{T}$ & rs11545078 & MTX & $\mathrm{C}$ & $\mathrm{T}$ \\
\hline MTHFD1 $1958 \mathrm{G}>\mathrm{A}$ & rs2236225 & MTX & $\mathrm{C}$ & $\mathrm{T}$ \\
\hline$T P M T * 2$ & rs 1800462 & MP & $\mathrm{C}$ & G \\
\hline$T P M T * 3 B$ & rs 1800460 & MP & A & $\mathrm{G}$ \\
\hline$T P M T * 3 C$ & rs 1142345 & MP & A & $\mathrm{G}$ \\
\hline$T P M T * 4$ & rs 1800584 & MP & A & $\mathrm{G}$ \\
\hline$A B C C 2$ & rs717620 & MTX & A & $\mathrm{G}$ \\
\hline SMARCA4 & rs1122608 & $\mathrm{GC}$ & G & $\mathrm{T}$ \\
\hline$A R I D 5 B$ & rs10821936 & MTX & $\mathrm{C}$ & $\mathrm{T}$ \\
\hline ITPA IVS $2+21 \mathrm{~A}>\mathrm{C}$ & rs7270101 & MP & A & $\mathrm{C}$ \\
\hline$X D H \mathrm{~A}(1936)>\mathrm{G}$ & rs 17323225 & MTX & $\mathrm{C}$ & $\mathrm{T}$ \\
\hline$X D H \mathrm{~A}(2107)>\mathrm{G}$ & rs 17011368 & MTX & $\mathrm{C}$ & $\mathrm{T}$ \\
\hline$N R 3 C 1$ & rs852977 & GC & A & G \\
\hline СYР3A & rs 10264272 & GC & $\mathrm{C}$ & $\mathrm{T}$ \\
\hline СYР3A4 & rs4986913 & GC & $\mathrm{C}$ & $\mathrm{T}$ \\
\hline
\end{tabular}

(MTX $=$ methotrexate, $\mathrm{MP}=$ mercaptopurine, $\mathrm{GC}=$ glucocorticoids $).$

der to avoid any association error [3,4]. Since the Brazilian population has a heterogeneous genetic background [18], studies have suggested that control for stratification using AIMs may be better for ensuring proper drug treatment according to the pharmacogenetics of the patient [26]. This is in preference to using a combination of the patients' physical traits, such as skin pigmentation combined with data extrapolated from other well-defined ethnic populations. In this study, we aimed to evaluate 20 different pharmacogenetic SNPs related to ALL drug response regarding population genetic differences between phase 3 HapMap populations [1] and the Brazilian population. In addition, we assessed correlation between SNP genotypes and genetic ancestry as inferred by the use of AIMs in the Brazilian population.

\section{Methods}

\subsection{Population sample}

The Brazilian population sample (BRA) consisted of 200 healthy, unrelated individuals, randomly selected from investigation of paternity cases. Individuals had no cost and signed an informed consent enabling the use of their DNA for paternity testing and further anonymous population genetic research. The sample was subdivided based on geographical origin, into groups of
40 individuals from the five Brazilian geopolitical regions: Center-West (CW), Northeast (NE), North (N), Southeast (SE) and South (S) [18]. The 11 HapMap population genotypes of the 20 SNPs were obtained from the Phase 3 HapMap database. The population description and abbreviations in HapMap are as follows: African ancestry in Southwest USA (ASW); Utah residents with Northern and Western European ancestry from the CEPH collection (CEU); Han Chinese in Beijing, China (CHB); Chinese in Metropolitan Denver, Colorado (CHD); Gujarati Indians in Houston, Texas (GIH); Japanese in Tokyo, Japan (JPT); Luhya in Webuye, Kenya (LWK); Mexican ancestry in Los Angeles, California (MEX); Maasai in Kinyawa, Kenya (MKK); Toscans in Italy (TSI); Yoruba in Ibadan, Nigeria (YRI).

\subsection{SNP selection and genotyping assay}

SNPs related to drug response, focusing on those used in ALL treatment protocols, especially those related to methotrexate metabolism, were selected from the pharmacogenetics database (PharmgKB) and also from the literature $[10,13,24]$. We selected 20 SNPs mapping to 13 genes (Table 1). PCR was performed in multiplex panels using the Qiagen Multiplex PCR Kit. After PCR, excess deoxyribonucleotide (dNTP) and primers were enzymatically eliminated using Exonuclease I and shrimp alkaline phosphatase. Single-base extension was carried out using the SNaPshot Multi- 
Table 2

Allelic frequencies of the 20 pharmacogenetic loci in 12 different populations $(\mathrm{n} / \mathrm{a}=$ data not available)

\begin{tabular}{|c|c|c|c|c|c|c|c|c|c|c|c|c|c|c|}
\hline \multirow[t]{2}{*}{ Locus } & \multirow[t]{2}{*}{ dbSNP ID } & \multirow[t]{2}{*}{ Allele } & \multicolumn{12}{|c|}{ Population } \\
\hline & & & ASW & $\overline{\mathrm{CEU}}$ & $\mathrm{CHB}$ & CHD & GIH & JPT & LWK & MEX & MKK & TSI & YRI & BRA \\
\hline MTHFR 677C>T & rs1801133 & $\mathrm{C}$ & 0.877 & 0.690 & 0.524 & 0.659 & 0.830 & 0.640 & 0.911 & 0.580 & 0.916 & 0.540 & 0.907 & 0.655 \\
\hline MTHFR 1298A >C & rs 1801131 & A & 0.811 & 0.659 & 0.780 & 0.788 & 0.608 & 0.814 & 0.817 & 0.790 & 0.734 & 0.682 & 0.885 & 0.723 \\
\hline$G S T P 1313 \mathrm{~A}>\mathrm{G}$ & rs1695 & A & 0.547 & 0.593 & 0.810 & 0.794 & 0.670 & 0.907 & 0.494 & 0.450 & 0.643 & 0.693 & 0.606 & 0.658 \\
\hline$R F C 180 \mathrm{G}>\mathrm{A}$ & rs 1051266 & A & 0.472 & 0.438 & 0.500 & 0.465 & 0.392 & 0.558 & 0.739 & 0.330 & 0.773 & 0.449 & 0.690 & 0.480 \\
\hline GSTP1 A114V & rs1138272 & $\mathrm{C}$ & 0.972 & 0.903 & 1.000 & $\mathrm{n} / \mathrm{a}$ & 0.909 & 1.000 & 0.989 & 0.920 & 0.976 & 0.938 & 1.000 & 0.963 \\
\hline$G G H 452 \mathrm{C}>\mathrm{T}$ & rs11545078 & $\mathrm{C}$ & 0.953 & $\mathrm{n} / \mathrm{a}$ & $\mathrm{n} / \mathrm{a}$ & 0.933 & 0.824 & 0.861 & 0.931 & $\mathrm{n} / \mathrm{a}$ & 0.941 & 0.918 & 0.920 & 0.930 \\
\hline MTHFD1 1958G >A & rs2236225 & $\mathrm{C}$ & 0.792 & 0.584 & 0.795 & 0.813 & 0.523 & 0.733 & 0.767 & 0.410 & 0.629 & 0.591 & 0.810 & 0.578 \\
\hline$T P M T * 2$ & rs 1800462 & $\mathrm{C}$ & $\mathrm{n} / \mathrm{a}$ & $\mathrm{n} / \mathrm{a}$ & $\mathrm{n} / \mathrm{a}$ & $\mathrm{n} / \mathrm{a}$ & $\mathrm{n} / \mathrm{a}$ & $\mathrm{n} / \mathrm{a}$ & $\mathrm{n} / \mathrm{a}$ & $\mathrm{n} / \mathrm{a}$ & $\mathrm{n} / \mathrm{a}$ & $\mathrm{n} / \mathrm{a}$ & $\mathrm{n} / \mathrm{a}$ & 0.962 \\
\hline$T P M T * 3 B$ & rs 1800460 & A & $\mathrm{n} / \mathrm{a}$ & $\mathrm{n} / \mathrm{a}$ & $\mathrm{n} / \mathrm{a}$ & $\mathrm{n} / \mathrm{a}$ & $\mathrm{n} / \mathrm{a}$ & $\mathrm{n} / \mathrm{a}$ & $\mathrm{n} / \mathrm{a}$ & $\mathrm{n} / \mathrm{a}$ & $\mathrm{n} / \mathrm{a}$ & $\mathrm{n} / \mathrm{a}$ & $\mathrm{n} / \mathrm{a}$ & 0.028 \\
\hline$T P M T * 3 C$ & rs 1142345 & A & 0.915 & 0.973 & 0.994 & 0.971 & 0.977 & 0.983 & 0.882 & 0.920 & 0.979 & 0.994 & 0.956 & 0.952 \\
\hline$T P M T * 4$ & rs 1800584 & A & $\mathrm{n} / \mathrm{a}$ & 0.009 & $\mathrm{n} / \mathrm{a}$ & $\mathrm{n} / \mathrm{a}$ & $\mathrm{n} / \mathrm{a}$ & $\mathrm{n} / \mathrm{a}$ & $\mathrm{n} / \mathrm{a}$ & $\mathrm{n} / \mathrm{a}$ & $\mathrm{n} / \mathrm{a}$ & 0.006 & $\mathrm{n} / \mathrm{a}$ & 0.023 \\
\hline$A B C C 2$ & rs717620 & A & 0.028 & 0.181 & 0.214 & 0.208 & 0.074 & 0.192 & 0.022 & 0.240 & 0.049 & 0.205 & 0.031 & 0.185 \\
\hline SMARCA4 & rs1122608 & G & 0.981 & 0.743 & 0.911 & 0.929 & 0.761 & 0.907 & 0.972 & 0.840 & 0.948 & 0.750 & 1.000 & 0.802 \\
\hline$A R I D 5 B$ & rs10821936 & $\mathrm{C}$ & 0.160 & 0.310 & 0.321 & 0.387 & 0.608 & 0.320 & 0.178 & 0.370 & 0.199 & 0.398 & 0.200 & 0.374 \\
\hline ITPA IVS $2+21 \mathrm{~A}>\mathrm{C}$ & rs7270101 & A & $\mathrm{n} / \mathrm{a}$ & 0.872 & 1.000 & $\mathrm{n} / \mathrm{a}$ & 0.972 & 1.000 & 0.878 & 0.940 & 0.843 & 0.898 & 0.894 & 0.851 \\
\hline$X D H$ A $(1936)>\mathrm{G}$ & rs 17323225 & $\mathrm{C}$ & 0.019 & 0.035 & 0.006 & $\mathrm{n} / \mathrm{a}$ & 0.011 & 0.000 & 0.011 & 0.010 & 0.007 & 0.045 & 0.004 & 0.030 \\
\hline$X D H \mathrm{~A}(2107)>\mathrm{G}$ & rs17011368 & $\mathrm{C}$ & 0.142 & 0.040 & 0.000 & $\mathrm{n} / \mathrm{a}$ & 0.011 & 0.000 & 0.156 & 0.010 & 0.164 & 0.040 & 0.119 & 0.053 \\
\hline$N R 3 C 1$ & rs852977 & A & 0.642 & 0.668 & 0.899 & 0.865 & 0.812 & 0.919 & 0.622 & 0.810 & 0.689 & 0.648 & 0.673 & 0.720 \\
\hline CYP $3 A$ & rs 10264272 & $\mathrm{C}$ & 0.915 & 1.000 & 0.994 & $\mathrm{n} / \mathrm{a}$ & $\mathrm{n} / \mathrm{a}$ & 0.994 & 0.750 & 0.969 & 0.853 & 0.994 & 0.832 & 0.973 \\
\hline CYP $3 A 4$ & rs4986913 & $\mathrm{C}$ & $\mathrm{n} / \mathrm{a}$ & 1.000 & 0.994 & $\mathrm{n} / \mathrm{a}$ & $\mathrm{n} / \mathrm{a}$ & 1 & $\mathrm{n} / \mathrm{a}$ & 0.990 & $\mathrm{n} / \mathrm{a}$ & $\mathrm{n} / \mathrm{a}$ & 1 & 1 \\
\hline
\end{tabular}

plex kit reaction mix (Applied Biosystems). The products were analyzed on the ABI 3130 Genetic Analyzer (Applied Biosystems) using POP-6 polymer [17]. Genotypes were called using the GeneMapper version 4.0 software (Applied Biosystems).

The ancestry-informative markers were genotyped using SNaPshot Multiplex panels totaling 28 autosomal AIMs as described elsewhere [18], following basically the same aforementioned procedure. The selected AIMs were reported as having large allele frequency differences among European, West African, and Amerindian populations [18].

\subsection{Statistical analysis}

Estimates of allelic frequencies, tests of HardyWeinberg Equilibrium (HWE), AMOVA, F-statistics and pairwise Fst were carried out using algorithms implemented through the Arlequin 3.0 software [11]. The Whap software [23] was used to calculate singlemarker regression association between the pharmacogenetic SNPs and individual ancestry estimates used as quantitative traits in the BRA population.

\section{Results}

The allele frequencies of the 20 SNPs in the 12 different populations are displayed in Table 2. At present there are no genetic data for two SNPs (rs1800462
Table 3

Pairwise Fst estimates for the 20 pharmacogenetic SNPs between pairs of regional populations of Brazil. The inferior diagonal shows Fst values and the superior diagonal shows p-value

\begin{tabular}{lccccc}
\hline & $\mathrm{CW}$ & $\mathrm{NE}$ & $\mathrm{N}$ & $\mathrm{SE}$ & $\mathrm{S}$ \\
\hline $\mathrm{CW}$ & - & 0.081 & 0.306 & 0.414 & 0.243 \\
$\mathrm{NE}$ & 0.0092 & - & 0.567 & 0.135 & 0.540 \\
$\mathbf{N}$ & 0.0025 & 0.0005 & - & 0.342 & 0.288 \\
SE & 0.0006 & 0.0058 & 0.0026 & - & 0.189 \\
$\mathbf{S}$ & 0.0029 & 0.0021 & 0.0027 & 0.0039 & - \\
\hline
\end{tabular}

and rs1800460) for any of the HapMap populations and therefore they were excluded from the population analysis. The SNP rs1138272 was monomorphic in three HapMap populations (CHB, JPT and YRI); the SNPs rs1122608 (SMARCA4), rs17323225 (XDH) and rs10264272 (CYP3A5) were monomorphic only in the YRI, JPT and CEU populations respectively; the SNPs rs7270101 (ITPA) and rs17011368 (XDH) were monomorphic in two populations (CHB and JPT); and the SNP rs4986913 (CYP3A4) monomorphic in four populations (CEU, JPT, YRI and BRA).

In the Brazilian population (BRA) there was one SNP (rs4986913, CYP3A4) that was monomorphic (for the $\mathrm{C}$ allele). The $\mathrm{T}$ allele was present only in the CHB and MEX populations, and then at a very low frequency. For this SNP there are no data available for the remaining populations. All of the SNPs in the BRA population were in accordance with HWE expectations, indicating the absence of inbreeding or population stratification [30]. 
Table 4

Pairwise Fst estimates for 18 pharmacogenetic SNPs between pairs of populations

\begin{tabular}{lcccccccccccccc}
\hline & BRA & ASW & CEU & CHB & CHD & GIH & JPT & LWK & MEX & MKK & TSI & YRI \\
\hline BRA & - & $<0.01$ & 0.36 & $<0.01$ & $<0.01$ & $<0.01$ & $<0.01$ & $<0.01$ & $<0.01$ & $<0.01$ & 0.054 & $<0.01$ \\
ASW & 0.044 & - & $<0.01$ & $<0.01$ & $<0.01$ & $<0.01$ & $<0.01$ & $<0.01$ & $<0.01$ & $<0.01$ & $<0.01$ & $<0.01$ \\
CEU & $<0.001$ & 0.043 & - & $<0.01$ & $<0.01$ & $<0.01$ & $<0.01$ & $<0.01$ & $<0.01$ & $<0.01$ & $<0.01$ & $<0.01$ \\
CHB & 0.035 & 0.098 & 0.055 & - & 0.14 & $<0.01$ & $<0.01$ & $<0.01$ & $<0.01$ & $<0.01$ & $<0.01$ & $<0.01$ \\
CHD & 0.029 & 0.065 & 0.044 & 0.002 & - & $<0.01$ & 0.05 & $<0.01$ & $<0.01$ & $<0.01$ & $<0.01$ & $<0.01$ \\
GIH & 0.021 & 0.061 & 0.023 & 0.083 & 0.061 & - & $<0.01$ & $<0.01$ & $<0.01$ & $<0.01$ & $<0.01$ & $<0.01$ \\
JPT & 0.039 & 0.103 & 0.066 & 0.007 & 0.005 & 0.077 & - & $<0.01$ & $<0.01$ & $<0.01$ & $<0.01$ & $<0.01$ \\
LWK & 0.076 & 0.023 & 0.080 & 0.145 & 0.114 & 0.104 & 0.140 & - & $<0.01$ & $<0.01$ & $<0.01$ & 0.06 \\
MEX & 0.032 & 0.100 & 0.033 & 0.095 & 0.094 & 0.061 & 0.116 & 0.148 & - & $<0.01$ & $<0.01$ & $<0.01$ \\
MKK & 0.059 & 0.052 & 0.069 & 0.126 & 0.101 & 0.071 & 0.104 & 0.021 & 0.142 & - & $<0.01$ & $<0.01$ \\
TSI & 0.004 & 0.068 & 0.004 & 0.036 & 0.038 & 0.041 & 0.051 & 0.109 & 0.040 & 0.093 & - & $<0.01$ \\
YRI & 0.065 & 0.016 & 0.079 & 0.118 & 0.083 & 0.101 & 0.107 & 0.004 & 0.157 & 0.021 & 0.103 & - \\
\hline
\end{tabular}

Table 5

Regression beta coefficients of association between SNPs and genetic ancestry in the Brazilian sample

\begin{tabular}{lcccc}
\hline Locus & Allele & \multicolumn{3}{c}{ Ancestry } \\
\cline { 3 - 5 } & & EUR & AFR & AMR \\
\hline rs1801133 & $\mathrm{T}$ & 0.029 & -0.028 & -0.002 \\
rs1801131 & $\mathrm{C}$ & 0.013 & -0.004 & -0.009 \\
rs1695 & $\mathrm{G}$ & $-0.044^{*}$ & $0.036^{*}$ & 0.009 \\
rs1051266 & $\mathrm{A}$ & $-0.043^{*}$ & 0.016 & $0.027^{*}$ \\
rs1138272 & $\mathrm{T}$ & 0.057 & $-0.111^{*}$ & 0.023 \\
rs11545078 & $\mathrm{T}$ & 0.047 & -0.024 & -0.024 \\
rs2236225 & $\mathrm{A}$ & $0.055^{*}$ & $-0.05^{* *}$ & -0.005 \\
rs1800462 & $\mathrm{G}$ & 0.082 & $-0.128^{* *}$ & 0.018 \\
rs1800460 & $\mathrm{A}$ & -0.009 & 0.025 & -0.021 \\
rs1142345 & $\mathrm{G}$ & -0.022 & 0.03 & -0.009 \\
rs1800584 & $\mathrm{A}$ & 0.004 & 0.026 & -0.055 \\
rs717620 & $\mathrm{T}$ & 0.015 & -0.006 & -0.009 \\
rs1122608 & $\mathrm{T}$ & 0.049 & -0.022 & -0.029 \\
rs10821936 & $\mathrm{C}$ & -0.013 & 0.012 & 0.001 \\
rs7270101 & $\mathrm{C}$ & 0.032 & -0.014 & -0.019 \\
rs17323225 & $\mathrm{G}$ & 0.03 & 0.004 & -0.051 \\
rs17011368 & $\mathrm{G}$ & -0.03 & 0.026 & 0.005 \\
rs852977 & $\mathrm{G}$ & -0.004 & 0.013 & -0.009 \\
rs10264272 & $\mathrm{T}$ & $-0.179^{* *}$ & 0.067 & $0.082^{* *}$ \\
rs4986913 & $\mathrm{C}$ & & monomorphic \\
\hline
\end{tabular}

${ }^{*}$ p-value $<0,05$ and ${ }^{* *}$ p-value $<0,01$.

As it has a continental size, the Brazilian sample was divided into five equal subsamples (corresponding to the country's geopolitical regions), according to the subject's birth place. The pairwise Fst estimates based on the 20 SNPs in the BRA subsamples are displayed in Table 3. There were no significant values of Fst, and therefore the subsamples could be grouped into one BRA sample. Table 4 shows Fst estimates for all pairwise population comparisons at 18 loci. The p-value was significant for most of the population pairs, with the exception of the following pairs: BRA-CEU, BRATSI, CHB-CHD, CHD-JPT, and LWK-YRI. The lowest Fst value was between the BRA and CEU populations, and the highest was between MEX and YRI.
Thereafter, regression analysis between individual genetic ancestry in the BRA sample and the 19 polymorphic SNPs was performed. Six SNPs (rs1695 GSTP1, rs1051266 - RFC1, rs1138272 - GSTP1, rs2236225-MTHFD1, rs1800462 - TPMT*2, rs10264 $272-C Y P 3 A 5)$ showed significant correlation between allelic frequency and ancestry estimates (Table 5).

\section{Discussion}

The present study described the allelic frequencies of 20 pharmacogenetic polymorphisms in the Brazilian population, their comparison with HapMap populations and their correlation with genetic ancestry.

Few studies have investigated any of these 20 pharmacogenetic SNPs in other Brazilian samples. Of those that have, some showed similar frequency distribution when compared to our data. The frequency of the $\mathrm{G}$ allele of rs 1051266 (in the RFC1 gene) in a sample of 172 individuals was 0.500 [6] and in the present study, we found a comparable frequency of 0.520 . The A allele from SNP rs1695 (GSTP1 gene) showed a frequency of 0.687 when genotyped in 592 volunteers [25]. Its frequency in our sample was 0.658 , very similar to the other studies.

The pairwise Fst calculations among the Brazilian regions showed no significant $\mathrm{p}$-value, indicating no differences between the five regions of Brazil regarding the studied SNPs. As such all Brazilian regions could be grouped and considered as one non-structured population with regard to these pharmacogenetic polymorphisms. This knowledge is very important for planning future association studies using samples from all Brazilian regions. It minimizes concerns about potentially spurious associations due to population structure. 
The Brazilian population is considered to be one of the most heterogeneous in the world, resulting from the admixture between Europeans, Amerindians and Africans over a period of just over 500 years. In previous studies, the ancestry of the Brazilian population, estimated based on mtDNA which informs regarding the maternal lineage, indicated $33 \%$ Amerindian contribution and $28 \%$ African contribution in white Brazilians [2]. The paternal lineage, determined by chromosome Y, in white Brazilians demonstrated a majority of European ancestry [8]. These results indicated that the Brazilian population was formed by European men and African and Amerindian women, in accordance with the developmental history of the Brazil population [8, 20]. The samples used in the study showed autosomal ancestry of $77.1 \%$ European, $14.3 \%$ African and $8.5 \%$ Amerindian [18]. Some SNPs in our population had allelic frequencies more similar to African populations, while others were more similar to Europeans, reinforcing the hypothesis that the admixture should have led to the inheritance and segregation of linkage disequilibrium blocks during the historical formation of the current Brazilian population.

The comparisons of allelic frequencies of 18 SNPs showed greatest similarity levels for genetically closer populations; for example, the pairs BRA-CEU, BRATSI, CHB-CHD, CHD-JPT, LWK-YRI, had higher similarity estimates as demonstrated by Fst pairwise calculations. The Brazilian population had a higher similarity for these polymorphisms with European populations (CEU and TSI), especially with the CEU sample. The greatest level of population divergence for BRA was with the African sample, followed by the Asian.

For some loci it was not possible to group different populations from HapMap according to geographic region, because the populations showed significant Fst values between them (Table 4). This result shows that geographically proximate populations may not always be grouped together because they may present significant differences amongst their genetic loci. Thus, results for one population cannot be extrapolated to others in these cases. Interestingly, if allelic frequencies are different, then, drug response in the nearest populations should also be investigated to establish and validate the variability regarding drug response and side effects between and within groups, and between individuals of different ethnicities [15,31].

We found six loci that were correlated with ancestry, though none of the loci presented high correlation values (Table 5). The low correlation observed between pharmacogenetic SNP genotype and ancestry indicates that in the Brazilian population, even at loci with different frequencies among populations, geographic ancestry has low influence on the allele frequency. This is due to the intensive admixture of the population. In association studies, population homogeneity is important mostly in the case of admixed populations, such as the Brazilian population. Understanding the genetic diversity in case-control or cross-sectional studies of disease association and drug response is necessary in order to avoid bias or spurious results, and there exists a consensus that this understanding should be achieved using ancestry informative markers [3,4,7,26,28]. However the present dataset does not support this consensus as for these polymorphisms in the Brazilian population, ancestry has no association with SNP genotypes suggesting that it is not useful to consider AIMs in this case.

Results found with CYP2C9 shows how ancestry and population specific alleles can be poorly correlated in an admixed population [14,27]. This gene is responsible for the inactivation of important drugs and is important in pharmacogenetic studies concerning populations differences, as one of its alleles, CYP $2 C 9 * 5$, was reported only in populations of African origin [14, 27]. This polymorphism was found in a Brazilian subject self-declared as white that had individual genetic ancestry estimated as $92 \%$ European, $7.5 \%$ Amerindian, and $0.5 \%$ African. The analysis of the siblings and parents of this individual revealed that the African contribution was of maternal origin, as was the allele CYP2C9*5 [27]. This exemplifies that even small proportions of admixture can lead to adverse analytical risk in genetic research and drug response studies. Although studies show correlation between ancestry and response to treatment of ALL [5,32], the causes of these differences are not clear. To individualize the treatment it is necessary to study the genetic differences between individuals and not only between populations.

In conclusion, the present work reported a population study of pharmacogenetic polymorphisms related to the response to drugs used in treatment of ALL. The correlation between the genotypes at these loci and ancestry is low, and their frequencies differ between HapMap populations, even within the same geographic region. Genetic ancestry can influence the drug response in treatment of ALL [32], however the pharmacogenetic polymorphisms studied do not show a strong association with ancestry in an admixed population. These findings indicate that at least in the general Brazilian population, drug response phenotypes cannot 
be inferred by observing biogeographical ancestry, as it has been in other ALL studies [32]. It is necessary to go straight to DNA variation in loci that have been identified as influencing drug response. We would like to point out the importance of incorporating SNPs related to drug response in future treatment protocols in the Brazilian population. In such studies ancestry estimates may also be incorporated as a wider measure of genetic influence on drug response. In this study it was not possible to evaluate the importance of the pharmacogenetic polymorphisms in the response to treatment in ALL, however our group is studying the same SNPs in Brazilian patients with ALL under treatment.

\section{Acknowledgments}

Research supported by CNPq, FAP-DF and Universidade Católica de Brasília.

\section{References}

[1] D.M. Altshuler, R.A. Gibbs, L. Peltonen, E. Dermitzakis, S.F. Schaffner, F. Yu, P.E. Bonnen, P.I. de Bakker, P. Deloukas, S.B. Gabriel, R. Gwilliam, S. Hunt, M. Inouye, X. Jia, A. Palotie, M. Parkin, P. Whittaker, K. Chang, A. Hawes, L.R. Lewis, Y. Ren, D. Wheeler, D.M. Muzny, C. Barnes, K. Darvishi, M. Hurles, J.M. Korn, K. Kristiansson, C. Lee, S.A. McCarrol, J. Nemesh, A. Keinan, S.B. Montgomery, S. Pollack, A.L. Price, N. Soranzo, C. Gonzaga-Jauregui, V. Anttila, W. Brodeur, M.J. Daly, S. Leslie, G. McVean, L. Moutsianas, H. Nguyen, Q. Zhang, M.J. Ghori, R. McGinnis, W. McLaren, F. Takeuchi, S.R. Grossman, I. Shlyakhter, E.B. Hostetter, P.C. Sabeti, C.A. Adebamowo, M.W. Foster, D.R. Gordon, J. Licinio, M.C. Manca, P.A. Marshall, I. Matsuda, D. Ngare, V.O. Wang, D. Reddy, C.N. Rotimi, C.D. Royal, R.R. Sharp, C. Zeng, L.D. Brooksand J.E. McEwen, Integrating common and rare genetic variation in diverse human populations, Nature 467 (2010), $52-58$.

[2] J. Alves-Silva, M. da Silva Santos, P.E. Guimaraes, A.C. Ferreira, H.J. Bandelt, S.D. Penaand V.F. Prado, The ancestry of Brazilian mtDNA lineages, Am J Hum Genet 67 (2000), 444-461.

[3] J.S. Barnholtz-Sloan, R. Chakraborty, T.A. Sellersand A.G. Schwartz, Examining population stratification via individual ancestry estimates versus self-reported race, Cancer Epidemiol Biomarkers Prev 14 (2005), 1545-1551.

[4] J.S. Barnholtz-Sloan, B. McEvoy, M.D. Shriverand T.R. Rebbeck, Ancestry estimation and correction for population stratification in molecular epidemiologic association studies, Cancer Epidemiol Biomarkers Prev 17 (2008), 471-477.

[5] S. Bhatia, H.N. Sather, N.A. Heerema, M.E. Trigg, P.S. Gaynonand L.L. Robison, Racial and ethnic differences in survival of children with acute lymphoblastic leukemia, Blood 100 (2002), 1957-1964.
[6] J.M. Biselli, E.M. Goloni-Bertollo, B.L. Zampieri, R. Haddad, M.N. Eberlinand E.C. Pavarino-Bertelli, Genetic polymorphisms involved in folate metabolism and elevated plasma concentrations of homocysteine: maternal risk factors for Down syndrome in Brazil, Genet Mol Res 7 (2008), 33-42.

[7] K. Bryc, A. Auton, M.R. Nelson, J.R. Oksenberg, S.L. Hauser, S. Williams, A. Froment, J.M. Bodo, C. Wambebe, S.A. Tishkoffand C.D. Bustamante, Genome-wide patterns of population structure and admixture in West Africans and African Americans, Proc Natl Acad Sci U S A 107 (2010), 786-791.

[8] D.R. Carvalho-Silva, F.R. Santos, J. Rochaand S.D. Pena, The phylogeography of Brazilian Y-chromosome lineages, Am J Hum Genet 68 (2001), 281-286.

[9] M.H. Cheok, N. Pottier, L. Kagerand W.E. Evans, Pharmacogenetics in acute lymphoblastic leukemia, Semin Hematol 46 (2009), 39-51.

[10] M.L. Davidsen, K. Dalhoffand K. Schmiegelow, Pharmacogenetics influence treatment efficacy in childhood acute lymphoblastic leukemia, J Pediatr Hematol Oncol 30 (2008), 831849.

[11] L. Excoffier, G. Lavaland S. Schneider, Arlequin (version 3.0): An integrated software package for population genetics data analysis, Evol Bioinform Online 1 (2005), 47-50.

[12] S.L. Hider, I.N. Bruceand W. Thomson, The pharmacogenetics of methotrexate, Rheumatology (Oxford) 46 (2007), 15201524.

[13] H.J. Kang, Y. Oh, S.M. Chun, Y.J. Seo, H.Y. Shin, C.W. Kim, H.S. Ahnand B.D. Han, TotalPlex gene amplification using bulging primers for pharmacogenetic analysis of acute lymphoblastic leukemia, Mol Cell Probes 22 (2008), 193-200.

[14] J. Kirchheinerand J. Brockmoller, Clinical consequences of cytochrome P450 2C9 polymorphisms, Clin Pharmacol Ther 77 (2005), 1-16.

[15] S. Kishi, C. Cheng, D. French, D. Pei, S. Das, E.H. Cook, N. Hijiya, C. Rizzari, G.L. Rosner, T. Frudakis, C.H. Pui, W.E. Evansand M.V. Relling, Ancestry and pharmacogenetics of antileukemic drug toxicity, Blood 109 (2007), 4151-4157.

[16] J.M. Kremer, Toward a better understanding of methotrexate, Arthritis Rheum 50 (2004), 1370-1382.

[17] T.C. Lins, L.R. Nogueira, R.M. Lima, P. Gentil, R.J. Oliveiraand R.W. Pereira, A multiplex single-base extension protocol for genotyping Cdx2, FokI, BsmI, ApaI, and TaqI polymorphisms of the vitamin D receptor gene, Genet Mol Res 6 (2007), 316-324.

[18] T.C. Lins, R.G. Vieira, B.S. Abreu, D. Grattapagliaand R.W. Pereira, Genetic composition of Brazilian population samples based on a set of twenty-eight ancestry informative SNPs, Am J Hum Biol 22 (2010), 187-192.

[19] M. Onciu, Acute lymphoblastic leukemia, Hematol Oncol Clin North Am 23 (2009), 655-674.

[20] F.C. Parra, R.C. Amado, J.R. Lambertucci, J. Rocha, C.M. Antunesand S.D. Pena, Color and genomic ancestry in Brazilians, Proc Natl Acad Sci U S A 100 (2003), 177-182.

[21] C.H. Puiand W.E. Evans, Treatment of acute lymphoblastic leukemia, N Engl J Med 354 (2006), 166-178.

[22] C.H. Pui, M.V. Rellingand J.R. Downing, Acute lymphoblastic leukemia, N Engl J Med 350 (2004), 1535-1548.

[23] S. Purcell, M.J. Dalyand P.C. Sham, WHAP: haplotype-based association analysis, Bioinformatics 23 (2007), 255-256.

[24] J.C. Rocha, C. Cheng, W. Liu, S. Kishi, S. Das, E.H. Cook, J.T. Sandlund, J. Rubnitz, R. Ribeiro, D. Campana, C.H. Pui, W.E. Evansand M.V. Relling, Pharmacogenetics of outcome in children with acute lymphoblastic leukemia, Blood 105 (2005), 4752-4758. 
[25] A. Rossini, D.C. Rapozo, L.M. Amorim, J.M. Macedo, R. Medina, J.F. Neto, C.V. Galloand L.F. Pinto, Frequencies of GSTM1, GSTT1, and GSTP1 polymorphisms in a Brazilian population, Genet Mol Res 1 (2002), 233-240.

[26] G. Suarez-Kurtz, Pharmacogenomics in admixed populations, Trends Pharmacol Sci 26 (2005), 196-201.

[27] G. Suarez-Kurtz, R. Vianna-Jorge, J.A. Periniand S.D. Pena, Detection of CYP2C $9 * 5$ in a white Brazilian subject, Clin Pharmacol Ther 77 (2005), 587-588.

[28] H. Tang, T. Quertermous, B. Rodriguez, S.L. Kardia, X. Zhu, A. Brown, J.S. Pankow, M.A. Province, S.C. Hunt, E. Boerwinkle, N.J. Schorkand N.J. Risch, Genetic structure, selfidentified race/ethnicity, and confounding in case-control association studies, Am J Hum Genet 76 (2005), 268-275.

[29] H. Tianand B.N. Cronstein, Understanding the mechanisms of action of methotrexate: implications for the treatment of rheumatoid arthritis, Bull NYU Hosp Jt Dis 65 (2007), 168173.

[30] J.E. Wigginton, D.J. Cutlerand G.R. Abecasis, A note on exact tests of Hardy-Weinberg equilibrium, Am J Hum Genet 76 (2005), 887-893.

[31] J.F. Wilson, M.E. Weale, A.C. Smith, F. Gratrix, B. Fletcher, M.G. Thomas, N. Bradmanand D.B. Goldstein, Population genetic structure of variable drug response, Nat Genet 29 (2001), 265-269.

[32] J.J. Yang, C. Cheng, M. Devidas, X. Cao, Y. Fan, D. Campana, W. Yang, G. Neale, N.J. Cox, P. Scheet, M.J. Borowitz, N.J. Winick, P.L. Martin, C.L. Willman, W.P. Bowman, B.M. Camitta, A. Carroll, G.H. Reaman, W.L. Carroll, M. Loh, S.P. Hunger, C.H. Pui, W.E. Evansand M.V. Relling, Ancestry and pharmacogenomics of relapse in acute lymphoblastic leukemia, Nat Genet (2011). 


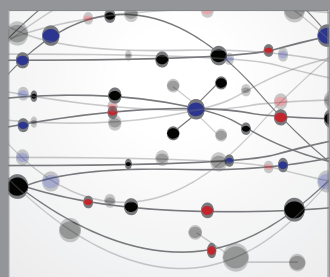

The Scientific World Journal
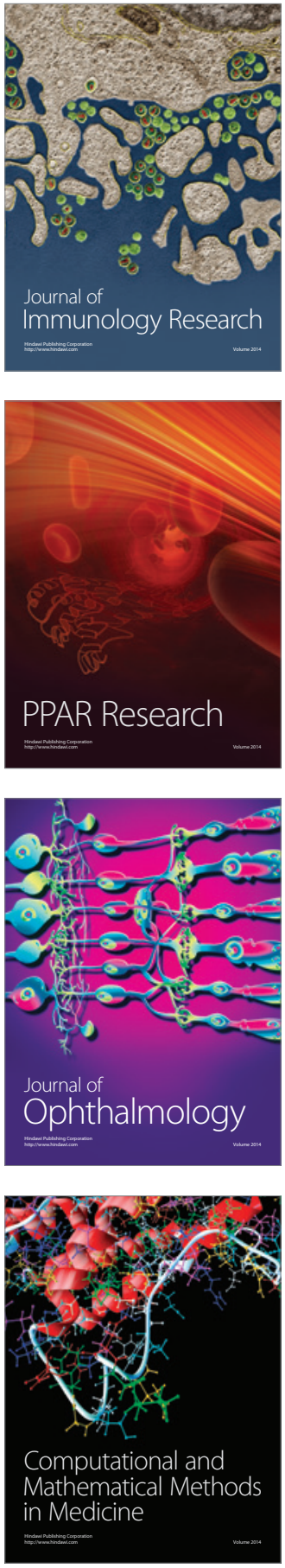

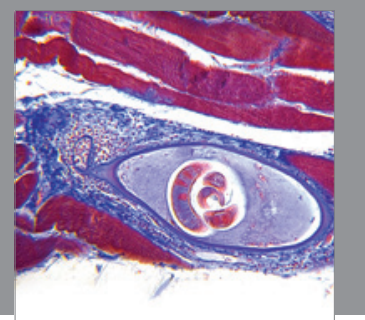

Gastroenterology

Research and Practice
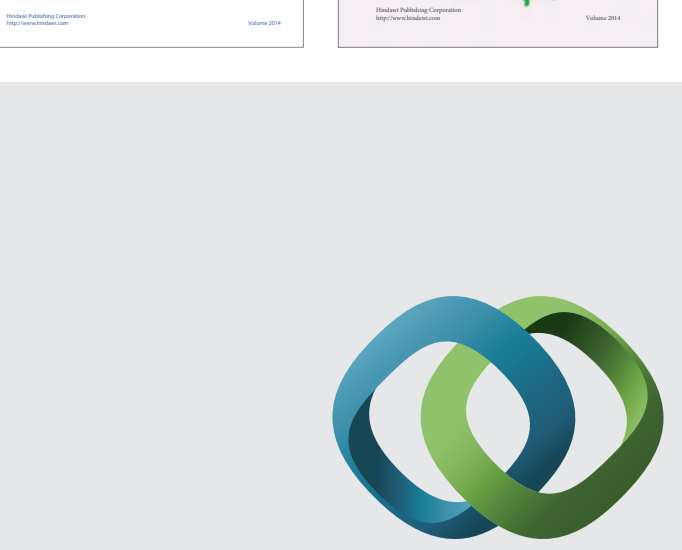

\section{Hindawi}

Submit your manuscripts at

http://www.hindawi.com
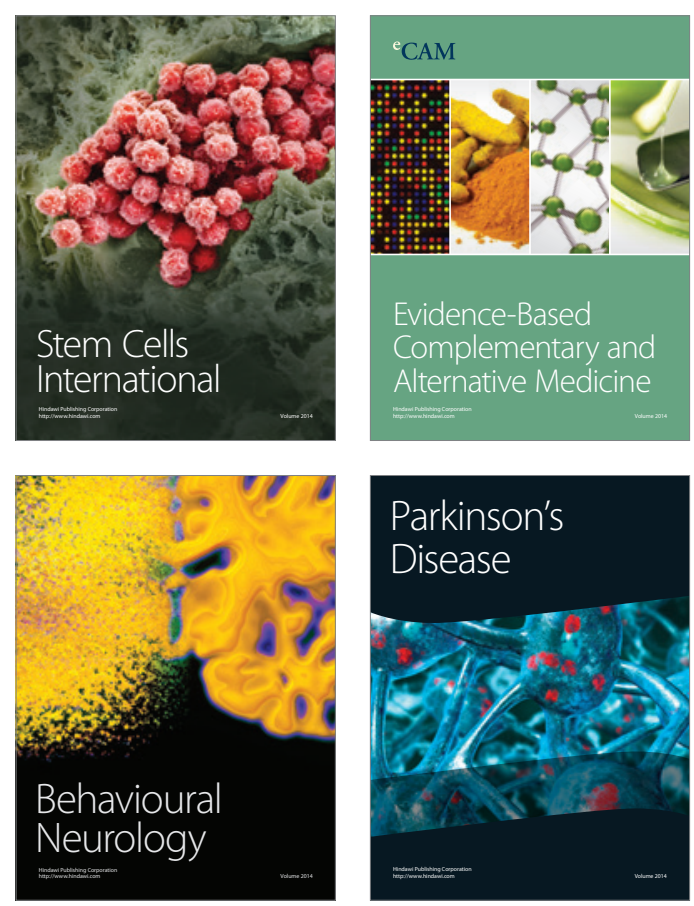

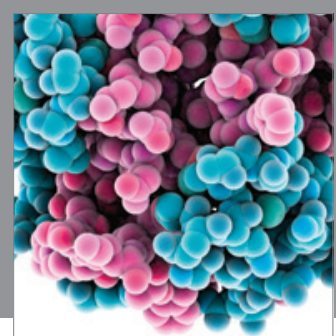

Journal of
Diabetes Research

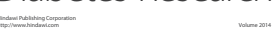

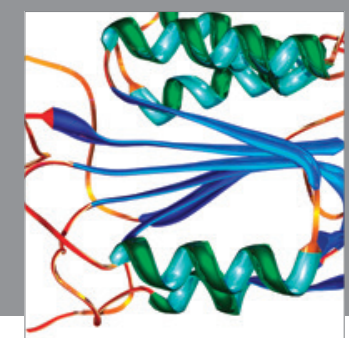

Disease Markers
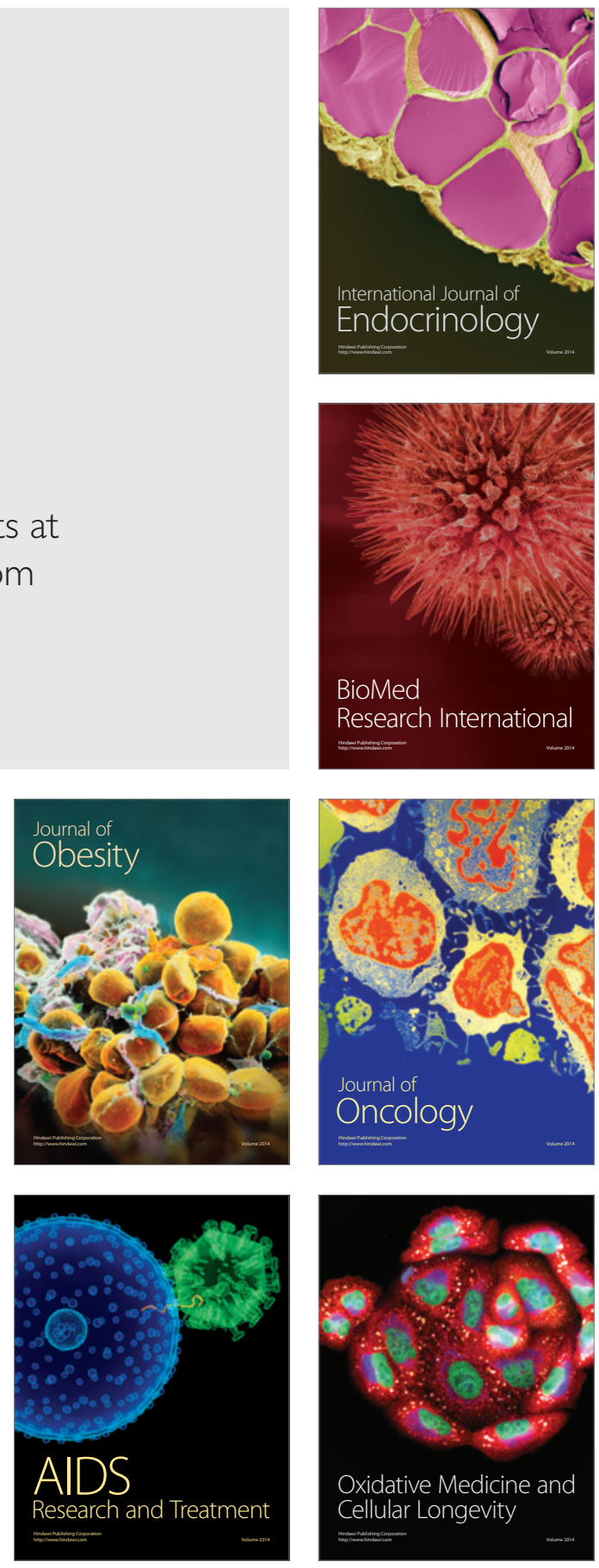